\title{
Pristimerin Inhibits Prostate Cancer Bone Metastasis by Targeting PC-3 Stem Cell Characteristics and VEGF-Induced Vasculogenesis of BM-EPCs
}

\author{
Shuai Huang ${ }^{\mathrm{a}}$ Peiheng $\mathrm{He}^{\mathrm{a}}$ Xinsheng Peng ${ }^{\mathrm{a}}$ Jinglei Li ${ }^{\mathrm{b}} \quad$ Dongliang $\mathrm{Xu}^{\mathrm{a}}$ \\ Yubo Tang ${ }^{c}$ \\ aDepartment of Orthopaedic Surgery, the First Affiliated Hospital of Sun Yat-sen University, Guangzhou, \\ bDepartment of Radiology, Guangdong Academy of Medical Sciences, Guangdong General Hospital, \\ Guangzhou, cDepartment of Pharmacy, the First Affiliated Hospital of Sun Yat-sen University, \\ Guangzhou, China
}

\section{Key Words}

Pristimerin • Bone metastasis • Prostate cancer cells • Stemness • Endothelial progenitor cells - Vasculogenesis

\begin{abstract}
Background/Aims: Prostate cancer ( $\mathrm{PCa}$ ) is one of the most common malignant cancers and a major leading cause of cancer deaths in men. Cancer stem-like cells are shown to be highly tumorigenic, pro-angiogenic and can significantly contribute to tumor new vessel formation and bone marrow derived-EPCs (BM-EPCs) are shown to recruit to the angiogenic switch in tumor growth and metastatic progression, suggesting the importance of targeting cancer stem cells (CSCs) and EPCs for novel tumor therapies. Pristimerin, an active component isolated from Celastraceae and Hippocrateaceae, has shown anti-tumor effects in some cell lines in previous studies. However, the effect and mechanism of Pristimerin on CSCs and EPCs in PCa bone metastasis are not well studied. Methods: The effect of Pristimerin on PC-3 stem cell characteristics and metastasis were detected by spheroid formation, CD133 and CD44 protein expression, matrix-gel invasive assay and colony-formation assay in vitro, VEGF and pro-inflammatory cytokines expression by ELISA assay, and tumor tumorigenicity by X-ray and MR in NOD-SCID mice model in vivo. In addition, we also detected the effect of Pristimerin on VEGF-induced vasculogenesis and protein expression of BM-EPCs. Results: Pristimerin could significantly inhibit spheroid formation and protein expression of CD133 and CD44, reduce VEGF and pro-inflammation cytokines expression of PC-3 cell, and prevent the xenografted PC-3 tumor growth in the bone of nude mice. The present data also showed that Pristimerin significantly inhibited VEGF-induced vasculogenesis of BM-EPCs by suppressing the EPCs functions including proliferation, adhesion, migration, tube formation and inactivation the

S. Huang and P. He contributed equally to this work.




\section{Cellular Physiology Cell Physiol Biochem 2015;37:253-268

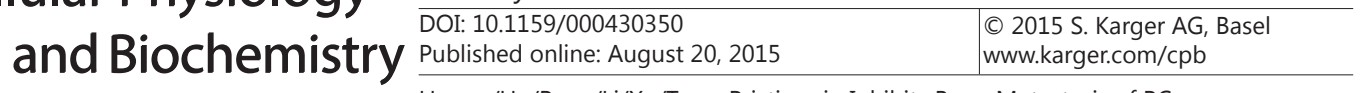 \\ Huang/He/Peng/Li/Xu/Tang: Pristimerin Inhibits Bone Metastasis of PCa}

phosphorylation of VEGFR-2, Akt and eNOS. Conclusion: These data provide evidence that Pristimerin has strong potential for development as a novel agent against prostate bone metastasis by suppressing PC-3 stem cell characteristics and VEGF-induced vasculogenesis of BM-EPCs.

Copyright (C) 2015 S. Karger AG, Basel

\section{Introduction}

Prostate Cancer ( $\mathrm{PCa}$ ) is the most common male malignancy in western countries and represents a major disease burden in the world. The principal problem arising from PCa is its propensity to metastasize to bone. Once tumors metastasize to bone, they are virtually incurable and result in significant disease morbidity prior to a patient's death [1-4]. Despite the high incidence and serious consequences of skeletal metastasis of prostate cancer, the mechanism underlying this osteotropism is unclear.

Recent identification of prostate cancer stem cells (CSCs) has provided a new insight into prostate carcinogenesis [5-8]. CSCs display unlimited proliferation potential, ability to self-renew, and capacity to generate a progeny of differentiated cells that constitute the major tumor population [9-11]. CSCs are the critical drivers of tumor progression and metastasis $[12,13]$. Moreover, the highly resistant nature of CSCs to different chemotherapies suggested that these cells may also contribute to treatment failure and disease relapse [14]. Most CSCs have been identified by cell-surface markers for the corresponding normal tissue stem/ progenitor cells. Prostate CSCs were first identified in prostate tumors using CD $44^{+} / \alpha_{2} \beta_{1}$ hi $\mathrm{CD} 133^{+}$as the cell surface markers [15]. Using similar approaches, CSCs have also been identified in prostate cancer cell lines PC-3 and LNCaP $[16,17]$.

Metastasis and neovascularization can be affected by many factors. Pro-inflammatory cytokines, including interleukin-1ß (IL-1ß,), interleukin-6 (IL-6), interleukin-8 (IL-8), and tumor necrosis factor-alpha (TNF- $\alpha$ ) could be prometastatic or proangiogenic and their deregulated expression directly correlate with the metastatic potential of several human carcinomas [18]. Therefore, anti-inflammatory drug may be an ideal strategy to inhibit PCa bone metastasis.

It may seem counterintuitive to expect that CSC, which by definition represent a very small minority of cells in a tumor, could make a significant contribution to tumor vasculogenesis. Indeed, transient bursts of angiogenic activity can be sufficient to initiate sustained tumor new vessel formation [19]. Therefore, it is possible that CSC provide the signals necessary to trip the "angiogenic switch" early during the growth of primary and/or metastatic tumors. An emerging area of research suggests that CSCs may also support tumor vasculogenesis that are partly dependent on increased expression of VEGF [20].

In cancer patients with metastasis, neovascularization-mediated progression of micrometastasis to lethal macrometastasis is the major cause of mortality [1]. Many studies have suggested that endothelial progenitor cells (EPCs) residing in the bone marrow can be recruited to tumor in response to tumor-derived cytokines, where they contribute to vascular development by incorporating into the walls of nascent capillaries [21]. CSCs have been shown to be highly pro-angiogenic compared with the majority of tumor cells [7]. VEGF is expressed in PCa at a high level [22-24], and its expression correlates with increasing grade, vascularity, and tumorigenicity $[24,25]$. Meanwhile, VEGF can promote vasculogenesis of EPC at the site of tumor neovascularization [26], in which EPCs differentiate into mature endothelial cells, and incorporate into growing tumor vessels [27, 28]. Notably, recent studies have shown that bone marrow derived-EPCs (BM-EPCs) are recruited to the angiogenic switch in tumor growth and metastatic progression [29-31].

Recent studies have shown that a number of botanical compounds have anti-CSC effect. Pristimerin, a naturally occurring quinonemethide triterpenoid compound isolated from Celastraceae and Hippocrateaceae, attracts considerable interest due to its potential chemopreventive and chemotherapeutic properties [32-34]. Pristimerin has antiinflammatory, antioxidant, antimalarial, and insecticidal activities and possess growth 


\section{Cellular Physiology Cell Physiol Biochem 2015;37:253-268

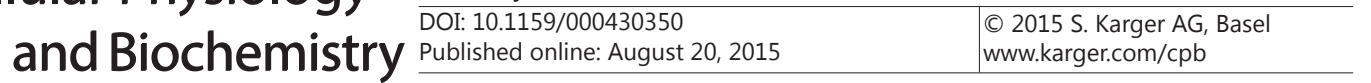 \\ Huang/He/Peng/Li/Xu/Tang: Pristimerin Inhibits Bone Metastasis of PCa}

inhibitory effect on a series of human cancer cell lines such as breast cancer, cervical cancer, multiple myeloma tumors, and prostate cancer [35-38]. However, the potential efficacy of Pristimerin against $\mathrm{PCa}$ bone metastasis remains unknown.

The aim of this study was to investigate whether Pristimerin, can inhibit the activies of human bone metastatic prostate cancer PC-3 cells and supress bone tumorigenicity of PC-3 cells in vivo, and, if so, through what mechanisms.

\section{Materials and Methods}

\section{Reagents}

The purity of Pristimerin (purity e98\%, Enzo Life Sciences, Lausen, Switzerland) used for experiments. Pristimerin was dissolved in dimethyl sulfoxide (DMSO, sigma, Saint Louis, USA) to a stock concentration of $50 \mathrm{mM}$ and then aliquoted and stored at $-20^{\circ} \mathrm{C}$.

\section{Culture conditions of PC-3 cell line}

Human prostatic adenocarcinoma PC-3 cell line was obtained from American Type Culture Collection (ATCC, Manassas, VA, USA) and maintained in F-12 medium (Hyclone, Logan, UT, USA) supplemented with $10 \%$ fetal bovine serum (FBS, Gibco-BRL), in a $37^{\circ} \mathrm{C}, 5 \% \mathrm{CO}_{2}$ environment at constant humidity.

\section{Isolation and cultivation of EPCs}

Bone marrow was collected from the drill holes of the pedicle during internal spine fixation of patients with lumbar degenerative diseases (15 patients, age range 59-72 years, mean age 63.28 years). Informed consent for bone marrow collection was obtained from the patients, and all procedures were performed in accordance with the guidance and approval of a research ethics committee in the First Affiliated Hospital of Sun Yat-sen University (NO.2008-55). The procedures for isolation, cultivation and identification of human EPC cultures followed previously published methods [39].

\section{Spheroid formation assay}

The spheroid formation assay was modified from a previously reported protocol [40]. Briefly, PC-3 cells were pre-treated with Pristimerin $(0,0.4,0.8,1.6 \mu \mathrm{M})$ for $24 \mathrm{~h}$ and then plated at the density of 400 cells/well on 6-well poly-HEMA (Sigma Aldrich, St. Louis, USA) -coated plates maintained in F-12 medium supplemented with B27 (1:50, Invitrogen, Carlsbad, CA, USA), 20 ng/mL EGF (BD Biosciences, San Jose, CA, USA), and $20 \mathrm{ng} / \mathrm{mL}$ bFGF (Invitrogen, Carlsbad, CA, USA) for $14 \mathrm{~d}$. After $14 \mathrm{~d}$, the number of prostaspheres (tight, spherical, nonadherent masses $>100 \mu \mathrm{m}$ in diameter) were counted, and images of prostaspheres were captured under the light microscope. For serial passage of primary spheres, the primary spheres were treated with Pristimerin for the above doses for $24 \mathrm{~h}$ and subsequently collected, dissociated with trypsin, and resuspended in F12 medium. After $14 \mathrm{~d}$, the number of prostaspheres (tight, spherical, nonadherent masses $>100 \mu \mathrm{m}$ in diameter) were counted, and images of prostaspheres were captured under the light microscope. Sphere formation efficiency $=$ colonies $/$ input cells $\times 100 \%$.

\section{In vitro invasion assay}

The invasion assay was done by using Transwell chamber consisting of $8 \mathrm{~mm}$ membrane filter inserts (Corning, NY, USA) coated with Matrigel (ECMatrix ${ }^{\mathrm{TM}}$, BD Biosciences, Heidelberg, Germany) as previously described [40]. Briefly, PC-3 cells were cultivated and treated with indicated concentrations of Pristimerin for $24 \mathrm{~h}$ and cells were trypsinized and suspended in serum-free medium. Then $1.5 \times 10^{5}$ cells were added to the upper chamber, whereas lower chamber was filled with medium with 10\% FBS. After incubated for 48 $\mathrm{h}$, cells were invaded through the coated membrane to the lower surface, in which cells were fixed with $4 \%$ paraformaldehyde and stained with $0.1 \%$ crystal violet for $30 \mathrm{~min}$ at room temperature. The cell count was done under the microscope $(100 \times)$.

Colony formation assay

Colony formation assay was performed as previously described [40, 41]. Brifely, PC-3 cells were cultivated and treated with indicated concentrations of Pristimerin for $24 \mathrm{~h}$ before they were plated onto 


\section{Cellular Physiology Cell Physiol Biochem 2015;37:253-268 \begin{tabular}{|l|l|}
\hline DOI: 10.1159/000430350 & (C) 2015 S. Karger AG, Basel
\end{tabular} \begin{tabular}{l|l} 
and Biochemistry Published online: August 20, 2015 & www.karger.com/cpb
\end{tabular} \\ Huang/He/Peng/Li/Xu/Tang: Pristimerin Inhibits Bone Metastasis of PCa}

a 65 -mm Petri dish at 300 cells as single cells for 12 days, and colonies were stained with crystal violet. Plating efficiency $=$ number of colonies ( $\geq 50$ cells per colony) per input cells $\times 100 \%$.

Enzyme-linked immunosorbent assay (ELISA)

Briefly, PC-3 cells grown in 24-well plates were treated with $(0,0.2,0.4,0.8 \mu \mathrm{M})$ of Pristimerin for 48 h. Cell supernatant was collected and centrifuged at $2,000 \mathrm{x}$ g at $4^{\circ} \mathrm{C}$ for $10 \mathrm{~min}$ to remove cell debris, and then used for ELISA assay of VEGF (Excell, Shanghai, China), IL-1ß (R\&D Systems, Minneapolis, MN, USA), IL-6 (R\&D Systems, Minneapolis, MN, USA), IL-8 (R\&D Systems, Minneapolis, MN, USA), and TNF- $\alpha$ (R\&D Systems, Minneapolis, MN, USA), according to the manufacturer's instructions.

Cell viability assay

Cell viability was determined by 2-(2-methoxy-4-nitrophenyl)-3-(4- nitrophenyl)-5-(2,4 -disulfophenyl)-2H-tetrazolium, monosodium salt (WST-8) assay kit (CCK-8, Dojindo, Japan). BM-EPCs $\left(5 \times 10^{3}\right.$ cells/well) were treated with Pristimerin $(0,0.2,0.4,0.8 \mu \mathrm{M})$ and/or without VEGF for 36 h. CCK-8 was used according to the manufacturer's instructions. WST- 8 was added into each well and incubated for 4 $\mathrm{h}$. The absorbance at $450 \mathrm{~nm}$ was measured using a microplate reader.

\section{Cell adhesion assay}

Cell-matrix adhesion assay. The cell-matrix adhesion assay was performed as previously described [42]. Briefly, human BM-EPCs were cultured for $24 \mathrm{~h}$ at $90 \%$ confluency and treated with Pristimerin $(0,0.2$, $0.4,0.8 \mu \mathrm{M}$ ) and/or without VEGF for $24 \mathrm{~h}$ as above. Then, BM-EPCs at $1 \times 104$ cells/well were plated onto fibronectin-coated 96 -well culture plates and incubated for $30 \mathrm{~min}$ at $37^{\circ} \mathrm{C}$. Thereafter, non-adherent cells were removed by washing three times with PBS. The adherent cells were fixed with $4 \%$ paraformaldehyde for $20 \mathrm{~min}$, washed with PBS, and stained with $0.1 \%$ crystal violet for $30 \mathrm{~min}$ at room temperature. Adherent cells were counted using a phase contrast microscope by independent, blinded investigators.

Cell-cell adhesion assay. For cell-cell adhesion assay, BM-EPCs were seeded at a density of $1 \times 104$ cells/ well in 96-well plate until confluency. Meanwhile, another group of BM-EPCs were cultured for $24 \mathrm{~h}$ at $90 \%$ confluency and treated with Pristimerin $(0,0.2,0.4,0.8 \mu \mathrm{M})$ and/or without VEGF, for $24 \mathrm{~h}$ as above. Then, the EPCs were labeled with 5-Chloromethylfluorescein Diacetate (CellTracker ${ }^{\mathrm{TM}}$ Green CMFDA, Invitrogen) and seeded at a density of $1 \times 104$ cells/well to the plate which containing $100 \%$ confluent EPC monolayer. The plate was incubated at $37^{\circ} \mathrm{C}$ for $30 \mathrm{~min}$. Thereafter, non-adherent cells were removed by washing three times with PBS. Adherent cells were counted under the fluorescence microscope (OLYPUMS IX81, JAPAN) by independent blinded investigators.

\section{EPCs migration assay}

A transwell migration assay was performed as described previously [43]. Briefly, BM-EPCs $\left(8 \times 10^{4}\right.$ cell/well) along with the Pristimerin $(0,0.2,0.4,0.8 \mu \mathrm{M})$ were seeded into the upper chambers. The bottom chambers were filled with $600 \mu \mathrm{L}$ EBM-2 supplemented with $10 \mathrm{ng} / \mathrm{mL}$ VEGF. The transwell system was incubated for $6-8 \mathrm{~h}$ in $5 \% \mathrm{CO}_{2}$ at $37^{\circ} \mathrm{C}$. Thereafter, non-migrating cells on the upper surface of the filter were removed using a cotton-tipped swab, and cells on the lower surface were stained with $1 \%$ crystal violet. Images were taken using an inverted microscope (Magnification, $\times 100$, OLYPUMS IX81, JAPAN).

\section{Capillary-like tube formation assay}

Tube formation was assessed as described previously [39]. Briefly, EPCs were pretreated with Pristimerin $(0,0.2,0.4,0.8 \mu \mathrm{M})$ for $30 \mathrm{~min}$, and then seeded onto the Matrigel layer in 96-well plates at a density of $1 \times 10^{4}$ cells with or without $10 \mathrm{ng} / \mathrm{mL}$ VEGF. Capillary-like tubes were imaged after $6-12 \mathrm{~h}$ incubation using an inverted microscope (Olympus; magnification, $\times 100$ ). All side branches were counted by three independent investigators in a blinded manner.

\section{Western blot}

To determine the effects of Pristimerin on the VEGFR2-dependent signaling pathway, BM-EPCs were first starved in serum-free EBM-2 for $6 \mathrm{~h}$, and then pretreated with or without Pristimerin for $30 \mathrm{~min}$, followed by the stimulation with $50 \mathrm{ng} / \mathrm{mL}$ of VEGF for $10 \mathrm{~min}$ (for VEGFR2 activation). Total protein was 


\section{Cellular Physiology Cell Physiol Biochem 2015;37:253-268

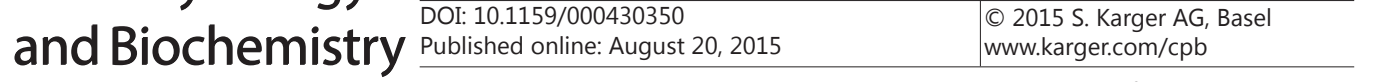 \\ Huang/He/Peng/Li/Xu/Tang: Pristimerin Inhibits Bone Metastasis of PCa}

extracted from the cultured cells using radioimmunoprecipitation lysis buffer with protease inhibitors, and the protein concentrations were determined using a DC Protein Assay Kit (Bio-Rad, Hercules, CA). Proteins were resolved on sodium dodecyl sulfate (SDS) polyacrylamide gel by electrophoresis and then transferred onto Hybond-P PVDF membrane (Amersham Biosciences, Piscataway, NJ). Then the membranes were blocked by $5 \%$ non-fat dry milk and incubated with primary antibodies against CD133 (Miltenyi Biotech, Auburn, CA), CD44 (Santa Cruz Biotechnology, Santa Cruz, CA), and phospho-VEGFR2, phospho-eNOS, phospho-Akt, VEGFR2, eNOS, Akt and $\alpha$-tubulin (Cell Signaling Technology) for $2 \mathrm{~h}$ at room temperature. After washing with TBST, the membrane was incubated with anti-rabbit IgG secondary antibodies, and the signals were visualized by chemiluminescence (ECL kit, Amersham, Piscataway, NJ). All immunoblots showed are representative of at least three independent experiments.

In vivo tumorigenicity assay

Intra-tibial injection model was used to determine whether Pristimerin can inhibit bone metastasis tumorigenicity. Six male severe combined immunodeficient (SCID) mice of 3-4 weeks old were purchased from HFK Bio-Technology.CO. LTD (Beijing, China). Before inoculation, PC-3 cells were treated with $1.6 \mu \mathrm{M}$ Pristimerin for $24 \mathrm{~h}$ and resuspended at the density of $3 \times 10^{5}$ cells per $40 \mu \mathrm{L}$, and injected into the tibia using a drilling motion. On the 5 th week, hind limbs were radiographed using a Faxitron X-ray machine (Faxitron X-ray Corp, USA) to detect the bone lesions. Bone lesions were evaluated and calculated where 0 grade for no lesion, 1 for minor lesions, 2 for small lesions, 3 for significant lesions with minor break of margins, and 4 for significant lesions with major break in peripheral lesions. Meanwhile, MRI (3.0 T MRI, GE Signa EXCITE HD) was used to detect the tumorigenicity. Subsequently, mice were sacrificed, and tibias were collected, decalcified and fixed in formalin for further histologic analysis.

Statistical analysis

All data are expressed as the mean \pm standard deviation from at least three individual experiments. Statistical comparisons between groups were performed by one-way ANOVA followed by Student's t-test using SPSS 16.0 software package. P values less than 0.05 were considered statistically significant.

\section{Results}

Pristimerin suppresses stem cell characteristics of PC-3 in vitro

The ability to form prostaspheres in non-adherent culture is one of the characteristics of prostate CSCs [44-46]. To test if Pristimerin treatment can inhibit prostate CSC properties, prostasphere formation of $\mathrm{PC}-3$ was studied in the presence or absence of Pristimerin. As shown in Fig. 1A and 1C, PC-3 cells cultured for $14 \mathrm{~d}$ under non-adherent conditions resulted in formation of prostaspheres, but the addition of Pristimerin drastically suppressed prostasphere formation. To further prove that Pristimerin is effective in inhibiting prostasphere formation, primary prostaspheres with enriched CSC population were dissociated and re-seeded into non-adherent culture plate to allow for the formation of secondary prostaspheres. Consistent with the result from the primary spheroid formation assay, Pristimerin treatment significantly suppressed the number of prostaspheres found in PC-3 cells, and the higher dosage of Pristimerin $(1.6 \mu \mathrm{M})$ completely eliminated all the secondary prostaspheres. To test if the anti-cancer effect of Pristimerin is through targeting of CSC properties, we then investigated whether Pristimerin treatment affects the expression of prostate CSC markers in PC-3 cell line, which has been reported to contain CSCs [47]. PC-3 cells were treated with $0.4,0.8$ and $1.6 \mu \mathrm{M}$ Pristimerin for $24 \mathrm{~h}$, the protein expression of CD133 and CD44 was examined by Western blot. As shown in Fig. 1E, expression of CD44 was significantly down-regulated after Pristimerin treatment in a dose-dependent manner. Downregulation of CD133 was also observed after Pristimerin treatment, although the effect was less obvious. All in all, the above results suggest that Pristimerin is able to significantly suppress the CSC properties of PC-3 cells. 


\section{Cellular Physiology Cell Physiol Biochem 2015;37:253-268 \begin{tabular}{l|l} 
DOI: 10.1159/000430350 & O 2015 S. Karger AG, Basel
\end{tabular} and Biochemistry Published online: August 20, 2015 www.karger.com/cpb

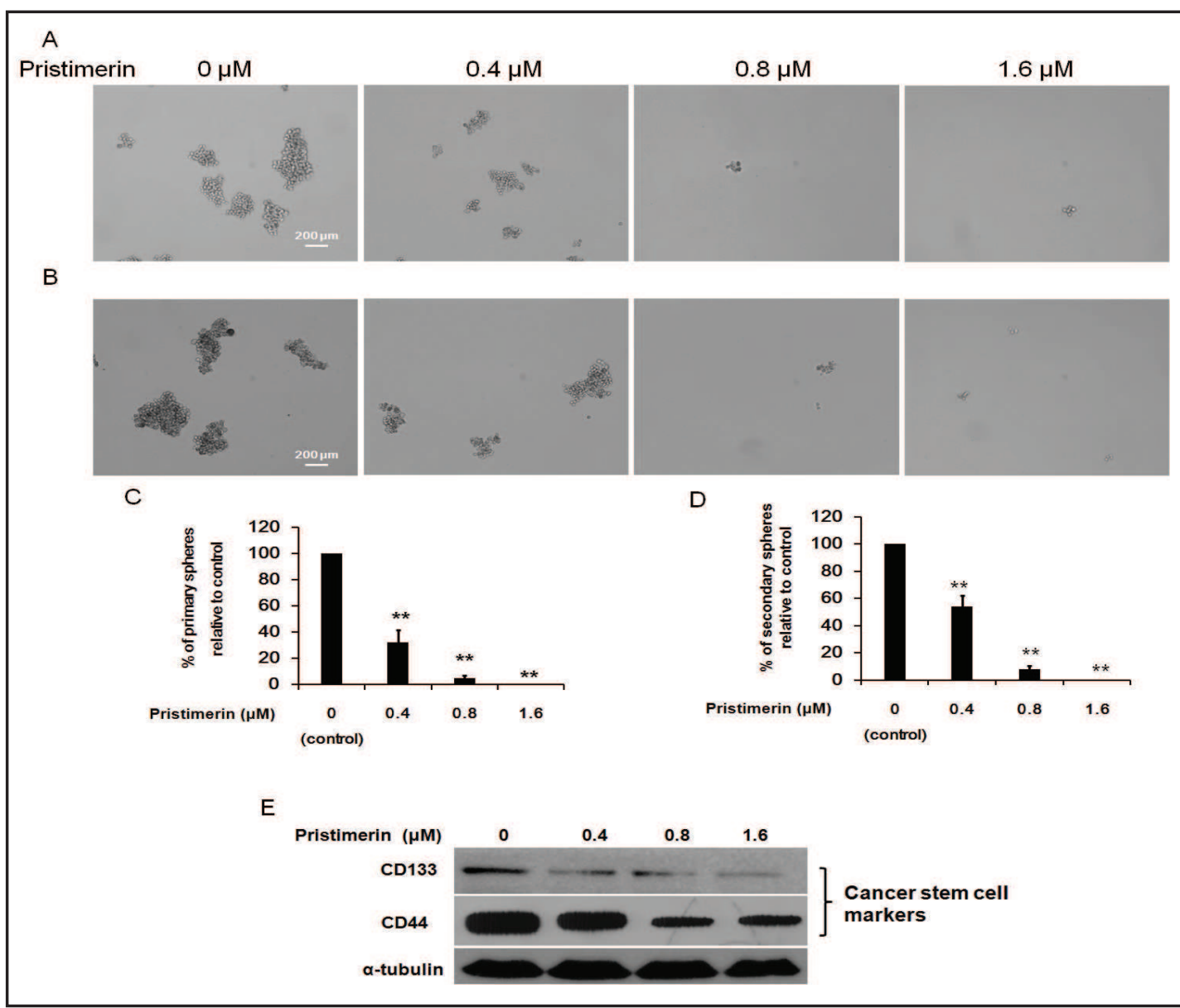

Fig. 1. Effects of Pristimerin on PC-3 CSC properties in vitro. (A) and (C) Spheroid formation assay was performed with PC-3 cells. Two hundred of cells were seeded onto polyHEMA pre-coated plates and treated with Pristimerin at different concentrations $(0,0.4,0.8$ and $1.6 \mu \mathrm{M})$ for $14 \mathrm{~d}$, and the number of prostaspheres formed was counted. Note that Pristimerin treatment efficiently suppresses the spheroid formation ability of PC-3 cells. Image of the prostaspheres was captured under microscope. Note that no prostaspheres can be found in cells treated with $1.6 \mu \mathrm{M}$ of Pristimerin. (B) and (D) Pristimerin inhibited the formation of secondary prostaspheres. Primary prostaspheres were dissociated and re-seeded into polyHEMA pre-coated plate. Pristimerin was added $24 \mathrm{~h}$ after the plating. Note that prostasphere formation was inhibited in a dose-dependent manner of Pristimerin. (E) Pristimerin down-regulates prostate CSC markers in PC-3 cells. Western blotting of prostate CSC markers CD44 and CD133 in PC-3 cells after Pristimerin treatment. Note that Pristimerin significantly down-regulates both stem cell markers in a dose-dependent manner. Data are presented as mean $\pm \mathrm{SD},{ }^{* *} P<0.01$.

\section{Pristimerin reduces prostate cancer bone metastasis in vitro}

To investigate the role of Pristimerin in the development and progression of PCa bone metastasis, matrix-gel invasion assay and colony formation assays were performed in vitro. The invasive property of PC-3 cells was examined by Transwell-Matrigel penetration assay, which depicted significantly fewer cells were penetrated through the gel-membrane when PC-3 cells treated by Pristimerin in a dose-dependent manner (Fig. 2 A and C). To determine efficiency of Pristimerin in inhibiting colony formation of PC-3 in vitro, colony-forming assay was performed. As shown in Fig. 2B and D, the number of colonies (\% plating efficiency) were reduced in PC-3 cells pre-treated by Pristimerin in a dose-dependent manner. All in all, the above results suggest that Pristimerin is able to significantly suppress the bone metastasis of PC-3 in vitro. 


\section{Cellular Physiology Cell Physiol Biochem 2015;37:253-268 \begin{tabular}{l|l|l}
\hline DOI: 10.1159/000430350 & ( 2015 S. Karger AG, Basel
\end{tabular} \begin{tabular}{l|l} 
and Biochemistry Published online: August 20, 2015 & www.karger.com/cpb \\
\hline
\end{tabular}

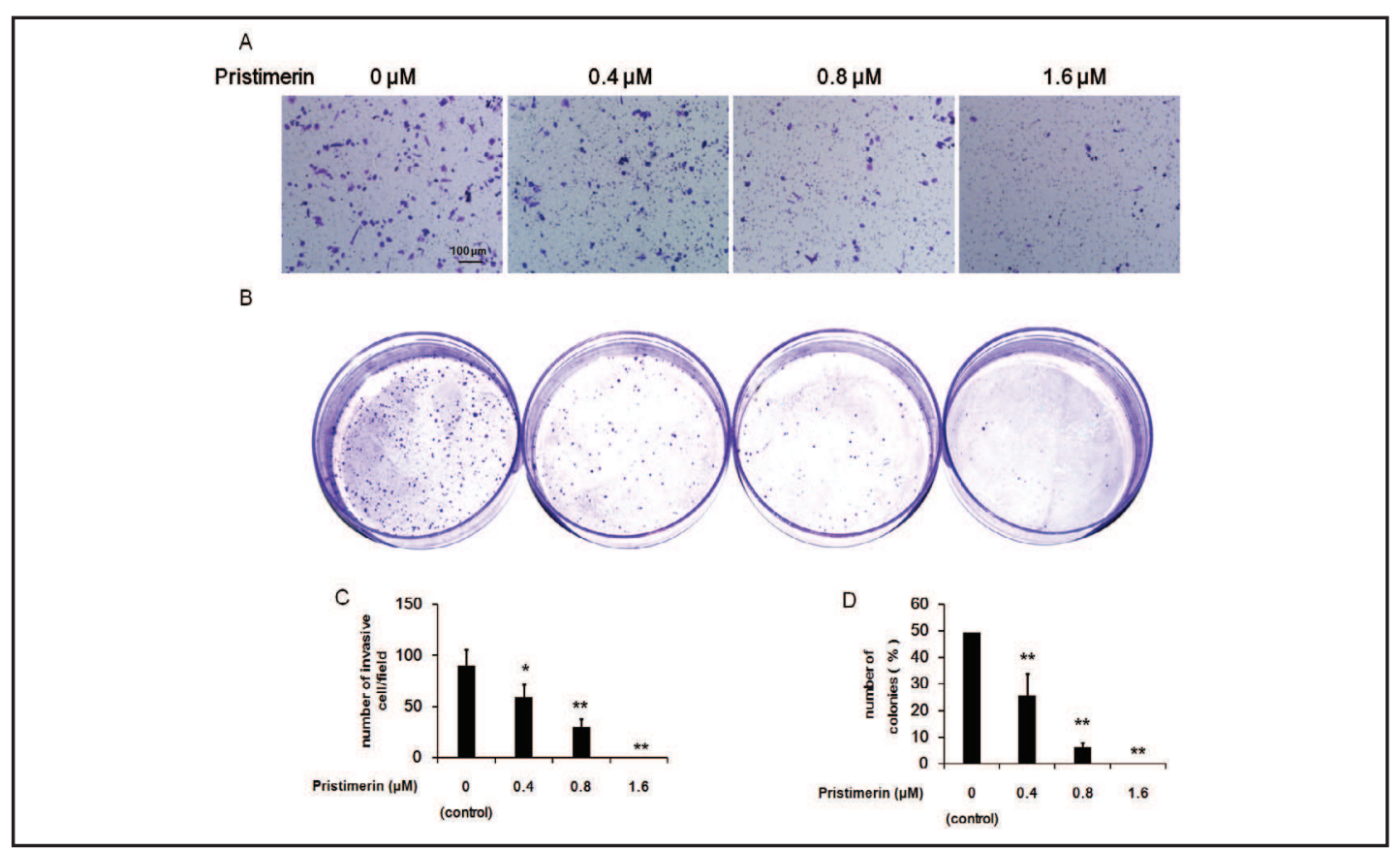

Fig. 2. Pristimerin repressed the bone metastasis of PC-3 cells in vitro. (A) and (C) The invasive properties of indicated cells were tested in invasion assay in a Transwell insert coated with Matrigel. Penetrated cells were counted and analyzed in histogram. Compared with the control group, Pristimerin significantly repressed the invasive ability of PC-3 cell. (B) and (D) Colony-formation exists in PC-3 cells. Compared with the control group, Pristimerin significantly repressed the number of colonies. Data are expressed as mean $\pm \mathrm{SD},{ }^{*} P<0.05,{ }^{* *} P<0.01$.

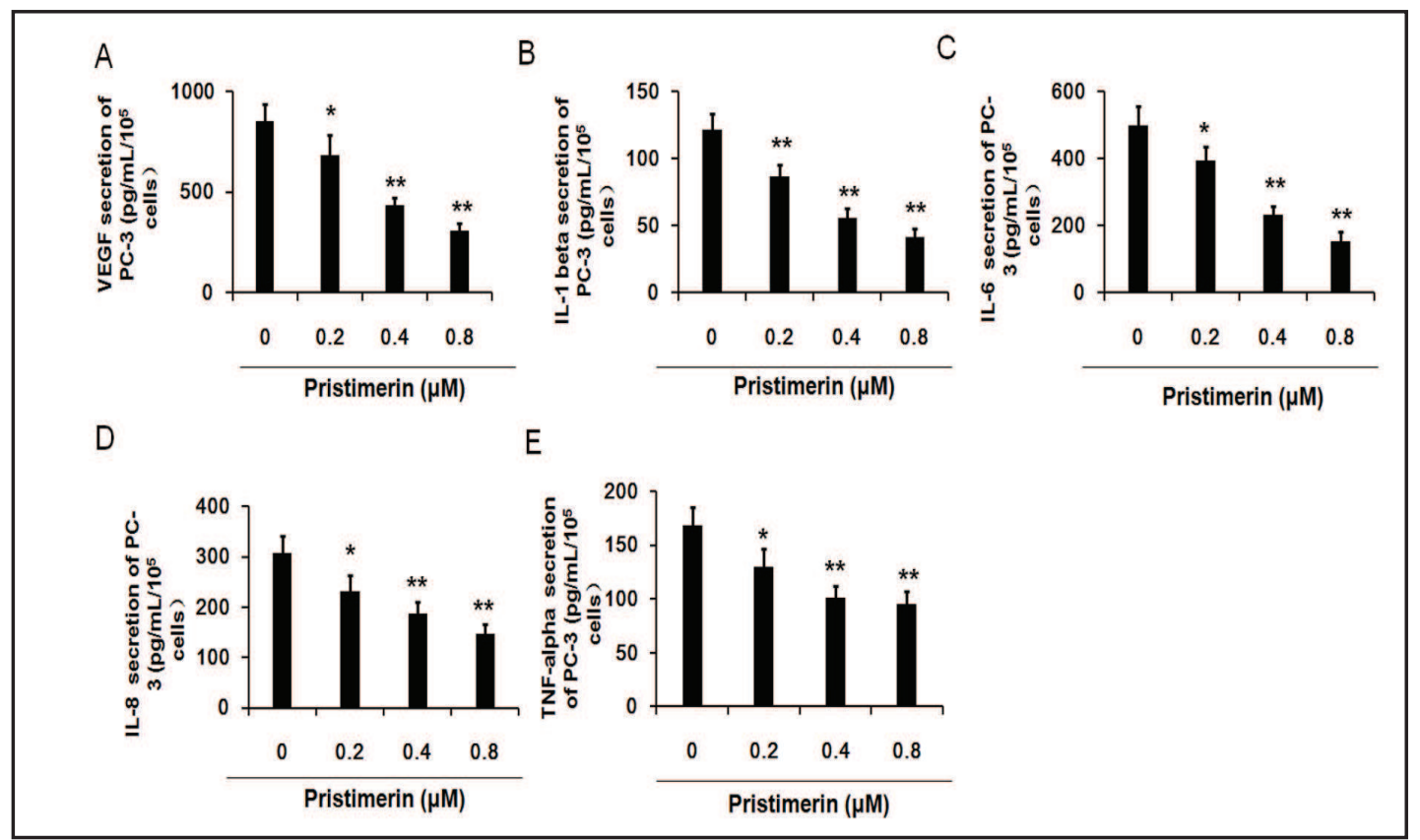

Fig. 3. Pristimerin inhibited VEGF and pro-inflammatory cytokine production in PC-3 cells. (A) Compared with the control group, VEGF secretion in PC-3 CM was inhibited by the pre-treated Pristimerin in a dose-depended manner $\left({ }^{*} \mathrm{P}<0.05\right.$, ${ }^{* *} \mathrm{P}<0.01$ ). (B-E) Pro-inflammatory cytokines such as IL-1ß, IL-6, IL-8, and TNF- $\alpha$ level were estimated by ELISA method according to the manufacturers' recommendations. (B) IL-1ß, (C) IL-6, (D) IL-8, and (E) TNF- $\alpha$. Data are expressed as mean \pm SD, ${ }^{*} \mathrm{p}<0.05,{ }^{* *} P<0.01$. 


\section{Cellular Physiology Cell Physiol Biochem 2015;37:253-268 \begin{tabular}{l|l} 
and Biochemistry Published online: August 20, 2015 & $\begin{array}{l}\text { DO 2015 S. Karger AG, Basel } \\
\text { www.karger.com/cpb }\end{array}$ \\
\hline
\end{tabular}}

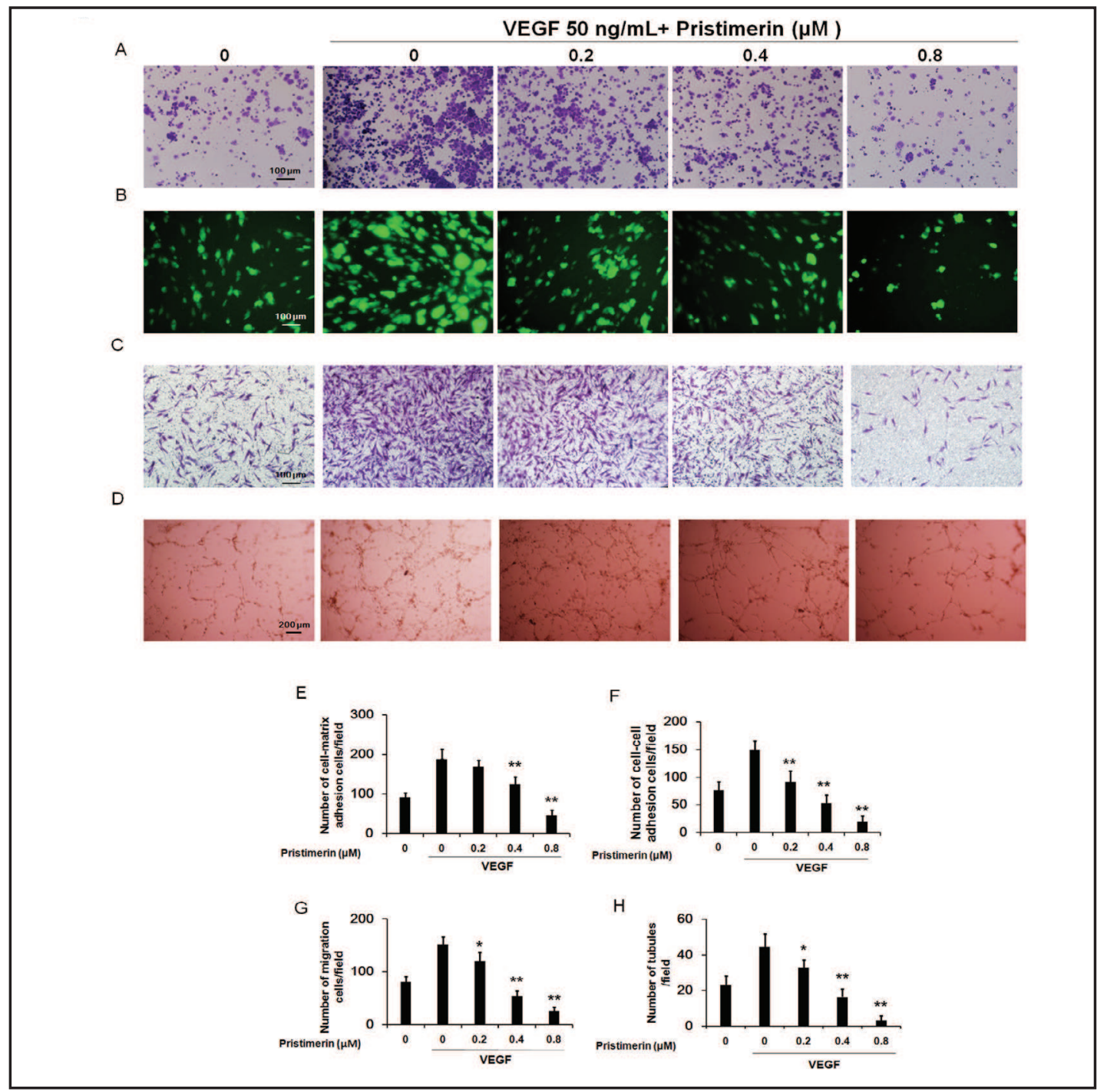

Fig. 4. Pristimerin suppressed the VEGF-induced functional activity of BM-EPCs. (A, E) Pristimerin inhibited VEGF-induced cell-matrix adhesion significantly at a low dose of $0.2 \mu \mathrm{M}$. Adherent cells were photographed (magnification, $\times 100)$ and quantified by manual counting. (B, F) Pristimerin inhibited VEGF-induced cellcell adhesion significantly at a low dose of $0.2 \mu \mathrm{M}$. (C, G) Pristimerin inhibited VEGF-induced chemotactic motility of BM-EPCs significantly at 0.4 and $0.8 \mu \mathrm{M}$. Migrated cells were photographed (magnification, $\times 100$ ) and quantified by manual individual cell counting. (D, H) Pristimerin inhibited VEGF-induced capillary structure formation significantly at a low dose of $0.2 \mu \mathrm{M}$. After incubation, BM-EPCs were fixed, and tubular structures were photographed (magnification, $\times 100$ ) quantified by manual counting. The results are representative of at least three individual experiments. (I) Cell viability was inhibited significantly by Pristimerin at a low dose of $0.2 \mu \mathrm{M}$ for $24 \mathrm{~h}$. The results are representative of at least three independent experiments. Data are expressed as mean $\pm \mathrm{SD},{ }^{*} \mathrm{p}<0.05,{ }^{* *} P<0.01$.

Pristimerin inhibits production of VEGF and pro-inflammatory cytokines in PC-3 cells

To further investigate the role of Pristimerin in VEGF and pro-inflammation cytokines expression in supernatant, ELISA assay was used. VEGF plays an important role in vasculogenesis by promoting BM-EPC proliferation, migration, and differentiation. As shown in Fig. 3A, Pristimerin treatment caused a dose-dependent and remarkable decrease in VEGF secretion. Furthermore, the pro-inflammatory cytokines production of IL-1ß (Fig. 3B), IL-6 (Fig. 3C), IL-8 (Fig. 3D), and TNF- $\alpha$ (Fig. 3E) were also significantly inhibited by Pristimerin in PC-3 cells in a dose-dependent manner. Taken together, our results suggested that 


\section{Cellular Physiology Cell Physiol Biochem 2015;37:253-268 \begin{tabular}{|l|l|}
\hline DOI: 10.1159/000430350 & O 2015 S. Karger AG, Basel
\end{tabular} and Biochemistry Published online: August 20, 2015 www.karger.com/cpb

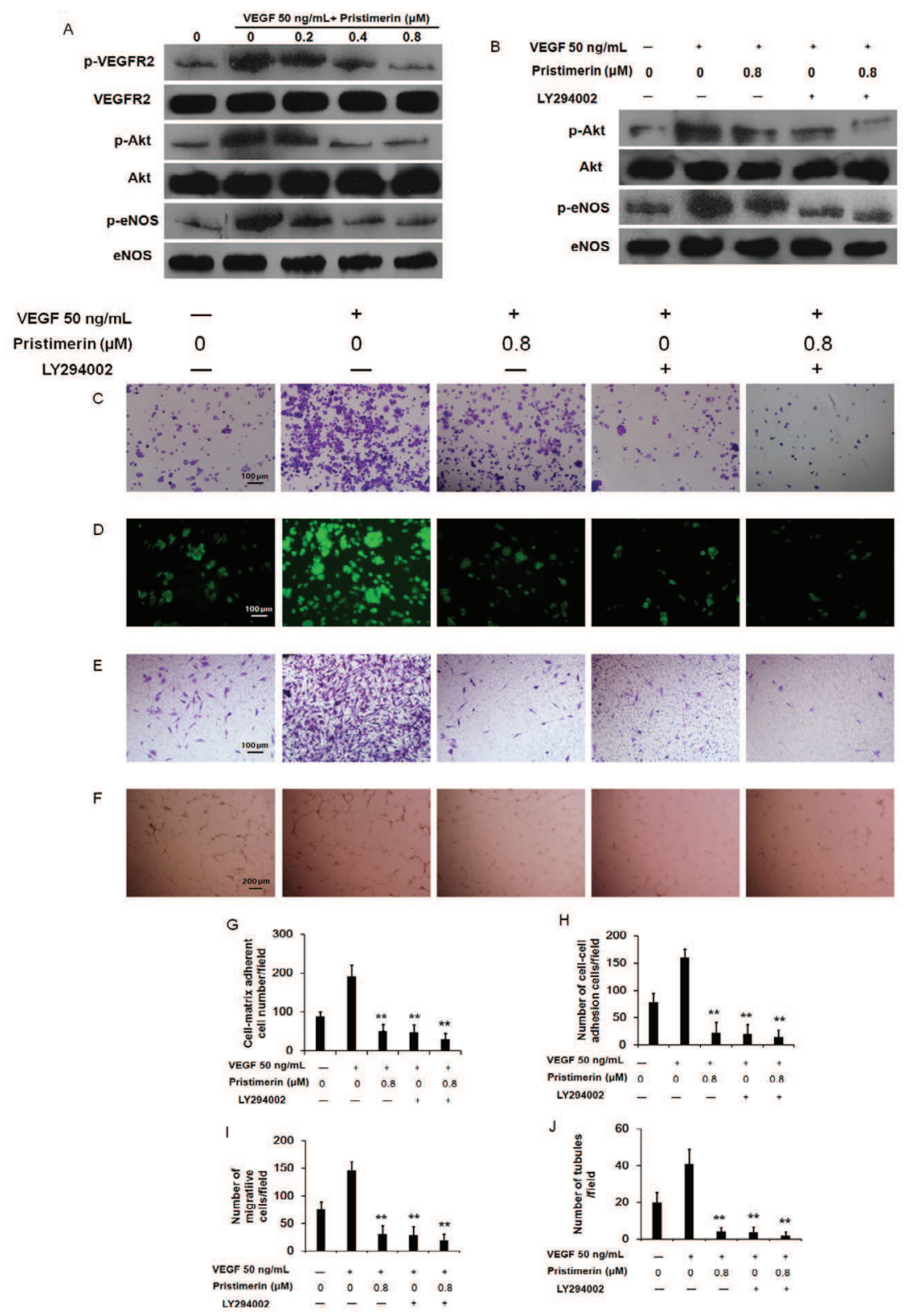

Fig. 5. (A) Pristimerin inhibited the VEGF-triggered activation of VEGFR-2 and Akt pathways in BM-EPCs. Cells were pretreated with Pristimerin for $30 \mathrm{~min}$ and incubated with VEGF for 10 min. VEGFR-2, Akt and eNOS were detected with phospho-specific antibodies by Western blot. Pristimerin suppressed the phosphorylation of p-VEGFR-2, p-Akt and p-eNOS triggered by VEGF in BM-EPCs. (B-J) BM-EPCs were pretreated with either LY294002 $(20 \mu \mathrm{M})$ for $60 \mathrm{~min}$, then cultured with VEGF or $0.8 \mu \mathrm{M}$ Pristimerin, and protein expression was determined by Western blot. Cell-matrix adhesion, cell-cell adhesion, cell migration and capillary structure formation were determined by the methods described above. Data are expressed as mean $\pm \mathrm{SD}, * * P<0.01$.

Pristimerin was effective in reducing the VEGF and pro-inflammatory cytokines production in the supernatant of PC-3 cell.

Pristimerin inhibits VEGF-induced vasculogenesis of BM-EPCS

To investigate the role of Pristimerin in VEGF-induced vasculogenesis of BM-EPCs, cell viability, cell migration, cell adhesion and capillary structure formation assays were 


\section{Cellular Physiology Cell Physiol Biochem 2015;37:253-268 \begin{tabular}{l|l} 
DOI: 10.1159/000430350 & O 2015 S. Karger AG, Basel
\end{tabular} and Biochemistry Published online: August 20, $2015 \quad$ www.karger.com/cpb

A
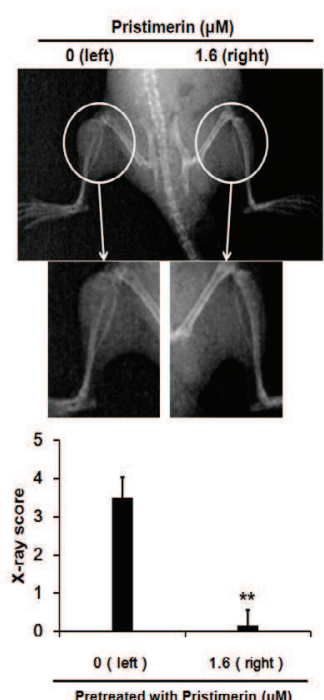

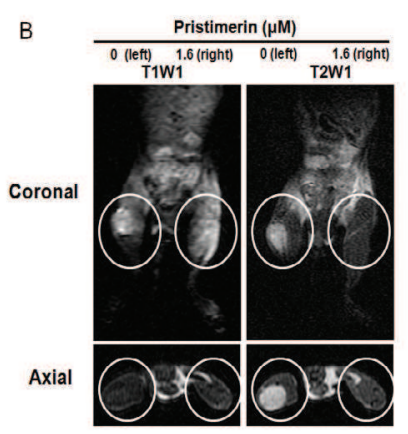

C

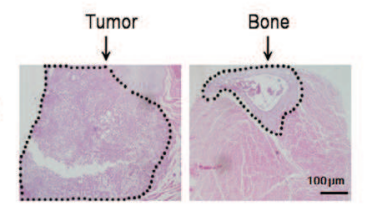

Fig. 6. Pristimerin repressed the tumorigenicity of PC-3 cells in bone. (A)Male SCID mice were inoculated with Pristimerin pre-treated PC-3 cells (left $0 \mu \mathrm{M}$ and right $1.6 \mu \mathrm{M}$ ) through the intra-tibial route. Skeletal lesions in radiographs are demonstrated. (B) MRI show pre-treated with Pristimerin $(1.6 \mu \mathrm{M})$ inhibited tumorigenicity of PC-3 cells in vivo. (C) Histologic analysis was carried out by H\&E-staining. Data are expressed as mean $\pm \mathrm{SD}, * * P<0.01$.

performed in vitro. To observe the possible cytotoxicity of Pristimerin on the cells, we examined whether Pristimerin modulates VEGF-induced cell viability of BM-EPCs by CCK-8 assay. As shown in Fig. 4I, incubation of BM-EPCs with Pristimerin for $24 \mathrm{~h}$ exhibited a dosedependent reduction in the number of BM-EPCs, with significant inhibition first occurring at a low dose of $0.2 \mu \mathrm{M}$. To investigate the possibility that Pristimerin alters the adhesiveness of EPCs, cells were incubated with Pristimerin for $24 \mathrm{~h}$. After replating on fibronectincoated dishes for $30 \mathrm{~min}$, EPCs pre-exposed to Pristimerin exhibited a significant decrease in the number of adhesive cells in a dose-dependent manner, with significant inhibition first occurring at $0.4 \mu \mathrm{M}$ and greater inhibition at $0.8 \mu \mathrm{M}$ (Fig. $4 \mathrm{~A}$ and E). Additionally, Pristimerin could markedly inhibit cell-cell adhesion with a much lower concentrations of $0.2 \mu \mathrm{M}$ (Fig. 4B and F). It is known that cell mobility and maintenance of cell survival signaling are essential for capillary tube formation. To assess the anti-angiogenic properties of Pristimerin in vitro, we examined the cellular response of Pristimerin-treated BM-EPCs to VEGF-induced migration using a transwell assay. Pristimerin reduced the migrative ability of BM-EPCs in a dose-dependent manner, with significant inhibition first occurring at $0.2 \mu \mathrm{M}$ and greater inhibition at 0.4 and $0.8 \mu \mathrm{M}$ (Fig. $4 \mathrm{C}$ and G). To further determine the effect of Pristimerin on vasculogenesis, we examined how Pristimerin regulates capillary tubule formation of BM-EPCs. When EPCs were seeded on Matrigel, robust tube-like structures were formed in the presence of VEGF. However, treatment with $0.2,0.4$ or $0.8 \mu \mathrm{M}$ of Pristimerin abolished the VEGF-induced tubule formation of BM-EPCs (Fig. 4D and H). These data suggest that Pristimerin has strong ability to inhibit VEGF-induced vasculogenesis of BM-EPCs in vitro.

Pristimerin inhibits activation of VEGFR2 and Akt/eNOS induced by VEGF in BM-EPCS

Interaction of VEGFR-2 with VEGF leads to the activation of various downstream signaling molecules responsible for EPC survival. To further delineate the mechanisms that contribute to the vasculogenesis inhibition effect of Pristimerin, we examined the signaling molecules involved in the VEGF pathway using Western blot analysis. As shown in Fig. 5A, phosphorylation of VEGFR-2 induced by VEGF was suppressed by Pristimerin in a dosedependent manner. Thus, the anti-angiogenic property of Pristimerin may be at least partially due to VEGFR-2 inhibition. Upon examination of the key pathway components that regulated 


\section{Cellular Physiology Cell Physiol Biochem 2015;37:253-268

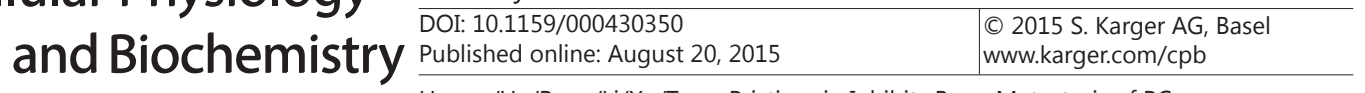 \\ Huang/He/Peng/Li/Xu/Tang: Pristimerin Inhibits Bone Metastasis of PCa}

the endothelial cell function in angiogenesis, we found that Pristimerin considerably suppressed the VEGF-induced phosphorylation of Akt and eNOS in BM-EPCs, while the total protein levels remained constant (Fig. 5A). These results suggest that Pristimerin may inhibit VEGF-induced vasculogenesis of BM-EPCs through blocking of these signaling pathways.

Furthermore, we used the highly specific PI3Kinhibitor LY294002 to assess the role of the PI3K/Akt pathway in angiogenesis. Unexpectedly, LY294002 inhibited not only Akt, but also notably phosphorylated eNOS (Fig. 5B). The present data also showed that the suppression of PI3K abolished the attenuated effect by Pristimerin on Akt/eNOS expression. Cell-matrix adhesion, cell-cell adhesion, cell migration and tube formation ability were significantly decreased when VEGF was co-administered with LY294002 (Fig. 5C-J), and inhibition of PI3K activity by LY294002 abolished the inhibitory effect on the cell functional activities imposed by Pristimerin. Taken together, these observations demonstrate that Pristimerin relies upon PI3K/Akt/eNOS to offer anti-angiogenic effect in BM-EPCs.

\section{Pristimerin inhibits tumorigenicity in vivo}

To further investigate the role of Pristimerin in tumorigenicity of PCa bone metastasis in vivo, an intra-tibial injection mouse model was used. The tumorigenicity were assessed by MRI, and the extents and areas of skeletal lesions were assessed by X-ray scores. Four weeks after intra-tibial inoculation, skeletal lesions of all animals in the left tibias were remarkably larger than those in the right tibias (Fig. 6A), which demonstrated PC-3 cells pretreated by Pristimerin had less skeletal invasive ability compared with control. Histological examinations using H\&E-stainning of the tissues showed that, when the Pristimerin-treated groups still retained normal tubular structures (Fig. 6B). MRI analysis displayed that PC-3 cells pretreated by Pristimerin revealed no tumor development (cannot be detected by MRI) and almost no bone invasion compared with control group (Fig. 6B). Histologic analysis was carried out by H\&E-staining in which tumors were lined out by dashed line as shown in the left panel and the normal bone tissue was lined out by dashed line in the right panel (microscope 40x, Fig. 6C). We could find out that bone was destroyed by the invasion of the tumor, but pretreatment by Pristimerin inhibited the bone destruction remarkably. Taken together, our results suggested that Pristimerin was effective in reducing the tumorigenic potential of bone metastasis in prostate cancer bone metastasis PC-3 cells.

\section{Discussion}

The evaluation of naturally occurring dietary compounds may indicate novel approaches for the treatment of prostate cancer, which remains one of the most lethal cancers despite tremendous scientific efforts. In our present work, for the first time, we systematically evaluated the chemopreventive effect of Pristimerin to bone metastasis and VEGF-induced vasculogenesis of BM-EPCs.

First, we found that pristimerin exerted significant inhibitory effects on stem-like properties of PC-3 cells. CSCs may be the critical drivers of tumor progression and metastasis $[12,13]$. Previously, many studies have used CD133 and CD44 as CSC characteristics. CD44+ PCa cells were shown to have the stem-like properties of increased tumorigenic, clonogenic, and metastatic potential [17]. Although CD44 does not seem to belong to the stemness genes, such as OCT4 and KLF4, that are central for maintaining stem cell characteristics, CD44 can contribute to the activation of stem cell regulatory genes and can be a target of these genes [48]. More importantly, a recent study has demonstrated that the transcriptional reprogramming led by nuclear CD44 has an active role in transforming cancer cells to a CSClike phenotypem [49]. Our results suggest that Pristimerin might play a significant role in the bone metastasis progression of PCa by regulating CSC characteristics. These prostate CSCs not only express high level of CD133 and CD44, but also are highly tumorigenic when compared to the non-CSC population. In the present study, we found that Pristimerin inhibited tumor sphere formation of PC-3 cells and repressed expression of CSC markers including 


\section{Cellular Physiology Cell Physiol Biochem 2015;37:253-268 \\ \begin{tabular}{l|l} 
and Biochemistry $10.1159 / 000430350$ & $\begin{array}{l}\text { Dublished online: August 20, } 2015 \\
\text { Pus. } 2015 \text { S. Karger AG, Basel } \\
\text { www.karger.com/cpb }\end{array}$ \\
\hline
\end{tabular} \\ Huang/He/Peng/Li/Xu/Tang: Pristimerin Inhibits Bone Metastasis of PCa}

CD133 and CD44 in PC-3 cells. Meanwhile, Pristimerin significantly inhibit bone metastasis in vitro and tumorigenicity in vivo. These findings demonstrate that Pristimerin negatively regulate the CSCs properties of PC-3 cells from PCa bone metastasis. And once stem cell characteristics were inhibited by Pristimerin, bone metastasis of prostate cancer PC-3 cells in vitro and tumorigenic in vivo were substantially suppressed. Importantly, this is the first report to demonstrate the effect of Pristimerin on suppression of stem cell characteristics leading to chemopreventive effect to bone metastasis of prostate cancer.

Several inflammatory cytokines have been linked with tumorigenesis, which suggests that inflammation is associated with cancer development [50]. TNF- $\alpha$ is a potent pleiotropic proinflammatory cytokine produced by macrophages, neutrophils, fibroblasts, keratinocytes, NK cells, and tumor cells [51]. The role of TNF- $\alpha$ has been linked to all steps of tumorigenesis, including cellular transformation, promotion, survival, proliferation, invasion, angiogenesis, and metastasis and B cells, and tumor cells $[52,53]$. IL-1 $\beta$ promotes the production of angiogenic proteins from host stromal or infiltrating cells in tumor microenvironment enhancing tumor growth and metastasis $[54,55]$. IL-6 and IL-8 are multifunctional cytokines, which showed profound angiogenic potential both ex vivo and in vivo, and are able to promote tumor growth and metastasis notably. Our results showed that Pristimerin treatment significantly decreased the elevated levels of VEGF and proinflammatory cytokines, IL-1 $\beta$, IL-6, IL-8, and TNF- $\alpha$ in PC-3 cells, which suggested that the anti-tumor effect of Pristimerin is associated with anti-inflammation in cancer.

Over the past 30 years, inhibition of new blood vessel formation has been accepted as an effective strategy to treat human cancer. BM-derived cells contribute to tumor neovasculature and, when modified to express a vessel formation inhibitor, can restrict tumor neovascularization. Extensive research has led to the identification and isolation of regulators of vasculogenesis, some of which represent therapeutic targets, such as VEGF. VEGF is expressed by prostate cancer at a high level, and its expression correlates with increasing grade, vascularity, and tumorigenicity $[24,25]$. Because VEGF can alter the marrow microenvironment from a quiescent state to a highly pro-angiogenic and pro-tumorigenic environment, it is important for the regulation of angiogenesis as well as cell function. Many studies have suggested that EPCs residing in the bone marrow can be recruited to the tumor in response to tumor derived cytokines, where they contribute to vascular development by incorporating into the walls of nascent capillaries [20, 21]. EPCs provide both instructive (release of pro-angiogenic cytokines, such as VEGF) and structural (vessel incorporation and stabilization) functions that contributing to the initiation of tumor neovasculogenesis. EPC recruitment may play a fraction. VEGF exerts its biological effects by binding to its receptor tyrosine kinases, expressed on BM-EPCs. VEGFR2 is the primary receptor mediating the angiogenic activity of VEGF through distinct signal transduction pathways that regulate BMEPCs proliferation, migration, differentiation and tube formation. Interruption of VEGFR2 signaling is thought to be necessary for tumor angiogenesis and macroscopic solid tumor growth [56]. Activation of VEGFR2 leads to the activation of various downstream signal transduction proteins, including extracellular signal-related kinase Akt and Akt-dependent eNOS phosphorylation [57, 58], which promotes the growth, migration, differentiation and cell viability of BM-EPCs in neovasculogenesis. Induction of apoptosis by Pristimerin involved activation of caspases, mitochondrial dysfunction, inhibition of anti-apoptotic nuclear factor- $\kappa \mathrm{B}$ (NF- $\mathrm{\kappa B}$ ) and Akt in ovarian carcinoma cells and pancreatic cancer cells [59, 60]. Pristimerin also induces apoptosis in prostate cancer cells predominately through the mitochondrial apoptotic pathway by inhibiting antiapoptic Bcl-2 through a reactive oxygen species-dependent ubiquitin-proteasomal degradation pathway [61]. Recent evidence shows that Pristimerin promotes degradation and inhibits phosphorylation of protein kinases in the Raf/MEK/ERK and PI3K/AKT/mTOR signaling pathways [62]. In the present study, we found that Pristimerin inhibited the elevated level of VEGF in PC-3 cells and could inhibit VEGF-induced vasculogenesis of BM-EPCs. And VEGF-induced phosphorylation of VEGFR-2, Akt and eNOS were also dramatically suppressed by Pristimerin. This finding indicates that Pristimerin inhibited the VEGF secretion of PC-3 and BM-EPCs, as a result, 


\section{Cellular Physiology Cell Physiol Biochem 2015;37:253-268 \begin{tabular}{l|l} 
DOI: 10.1159/000430350 & O 2015 S. Karger AG, Basel
\end{tabular} and Biochemistry Published online: August 20, 2015 www.karger.com/cpb \\ Huang/He/Peng/Li/Xu/Tang: Pristimerin Inhibits Bone Metastasis of PCa}

reduced the instructive functions of BM-EPCs, suggesting that Pristimerin targeting VEGF/ VEGFR-2 signaling is powerful and potential agent in cancer therapy.

Taken together with previous studies, Pristimerin has been identified as a candidate therapeutic agent to prevent bone metastasis. Specifically, Pristimerin may have therapeutic value in cancers where PC-3 stem cell characteristics and VEGF-induced vasculogenesis of BM-EPCs are stimulated. Furthermore, Pristimerin might be used for therapeutics in combination with anti-cancer agents and health foods to prevent and block progression of tumor development.

\section{Conclusions}

In conclusion, the present study highlights the ability of stemness inhibition on PC-3 cells and anti-angiogenic differentiation on BM-EPCs imposed by Pristimerin. Furthermore, Pristimerin also prevent the xenografted PC-3 tumor growth in vivo. In characterizing the mechanism of action, we discovered that inactivation of the PI3K/Akt/eNOS pathways is required for Pristimerin-mediated anti-angiogenic effect in BM-EPCs. Results of the present study suggest a better understanding of the mechanism of the anti-stemness and antiangiogenesis signaling cascade engaged by Pristimerin, that can identify potential targets for intervention to prevent bone metastasis of prostate cancer.

\section{Abbreviations}

PCa (prostate cancer); BM-EPC (bone marrow-derived endothelial progenitor cell); CSCs (cancer stem cells); eNOS (endothelial nitric oxide synthase); VEGF (vascular endothelial growth factor); VEGFR-2 (vascular endothelial growth factor receptor 2); TNF- $\alpha$ (tumor necrosis factor-alpha); IL-1ß (interleukin-1ß); IL-6 (interleukin-6); IL-8 (interleukin-8).

\section{Acknowledgements}

This work was supported by "Science and Technology Planning Project of GuangZhou, China" Grant (2011J4300102) and grants from the National Natural Science Foundation of China (No. 81272938).

\section{Disclosure Statement}

No potential conflicts of interest were disclosed.

\section{References}

1 Bubendorf L, Schopfer A, Wagner U, Sauter G, Moch H, Willi N, Gasser TC, Mihatsch MJ: Metastatic patterns of prostate cancer: An autopsy study of 1,589 patients. Hum Pathol 2000;31:578-583.

2 Gillies K, Wertman J, Charette N, Dupre DJ: Anterograde trafficking of cxcr4 and ccr2 receptors in a prostate cancer cell line. Cell Physiol Biochem 2013;32:74-85.

3 Shah RB, Mehra R, Chinnaiyan AM, Shen R, Ghosh D, Zhou M, Macvicar GR, Varambally S, Harwood J, Bismar TA, Kim R, Rubin MA, Pienta KJ: Androgen-independent prostate cancer is a heterogeneous group of diseases: Lessons from a rapid autopsy program. Cancer Res 2004;64:9209-9216.

4 Rana A, Chisholm GD, Khan M, Sekharjit SS, Merrick MV, Elton RA: Patterns of bone metastasis and their prognostic significance in patients with carcinoma of the prostate. Br J Urol 1993;72:933-936. 


\section{Cellular Physiology Cell Physiol Biochem 2015;37:253-268 \begin{tabular}{l|l|l}
\cline { 2 - 3 } DOI: 10.1159/000430350 & (C) 2015 S. Karger AG, Basel
\end{tabular} \begin{tabular}{l|l} 
and Biochemistry Published online: August 20, 2015 & www.karger.com/cpb
\end{tabular}}

Huang/He/Peng/Li/Xu/Tang: Pristimerin Inhibits Bone Metastasis of PCa

5 O'Brien CA, Kreso A, Jamieson CH: Cancer stem cells and self-renewal. Clin Cancer Res 2010;16:3113-3120.

6 Reya T, Morrison SJ, Clarke MF, Weissman IL: Stem cells, cancer, and cancer stem cells. Nature 2001;414:105-111.

7 Zhang K, Waxman DJ: Pc3 prostate tumor-initiating cells with molecular profile fam65bhigh/mfi2low/ lef1low increase tumor angiogenesis. Mol Cancer 2010;9:319.

8 Park DM, Rich JN: Biology of glioma cancer stem cells. Mol Cells 2009;28:7-12.

9 Clarke MF, Dick JE, Dirks PB, Eaves CJ, Jamieson CH, Jones DL, Visvader J, Weissman IL, Wahl GM: Cancer stem cells--perspectives on current status and future directions: Aacr workshop on cancer stem cells. Cancer Res 2006;66:9339-9344.

10 Sun S, Wang Z: Aldh high adenoid cystic carcinoma cells display cancer stem cell properties and are responsible for mediating metastasis. Biochem Biophys Res Commun 2010;396:843-848.

11 Visvader JE, Lindeman GJ: Cancer stem cells in solid tumours: Accumulating evidence and unresolved questions. Nat Rev Cancer 2008;8:755-768.

12 Chaffer CL, Weinberg RA: A perspective on cancer cell metastasis. Science 2011;331:1559-1564.

13 Monteiro J, Fodde R: Cancer stemness and metastasis: Therapeutic consequences and perspectives. Eur J Cancer 2010;46:1198-1203.

14 Scopelliti A, Cammareri P, Catalano V, Saladino V, Todaro M, Stassi G: Therapeutic implications of cancer initiating cells. Expert Opin Biol Ther 2009;9:1005-1016.

15 Collins AT, Berry PA, Hyde C, Stower MJ, Maitland NJ: Prospective identification of tumorigenic prostate cancer stem cells. Cancer Res 2005;65:10946-10951.

16 Li H, Chen X, Calhoun-Davis T, Claypool K, Tang DG: Pc3 human prostate carcinoma cell holoclones contain self-renewing tumor-initiating cells. Cancer Res 2008;68:1820-1825.

17 Patrawala L, Calhoun T, Schneider-Broussard R, Li H, Bhatia B, Tang S, Reilly JG, Chandra D, Zhou J, Claypool K, Coghlan L, Tang DG: Highly purified cd44+ prostate cancer cells from xenograft human tumors are enriched in tumorigenic and metastatic progenitor cells. Oncogene 2006;25:1696-1708.

18 Isner JM, Asahara T: Angiogenesis and vasculogenesis as therapeutic strategies for postnatal neovascularization. J Clin Invest 1999;103:1231-1236.

19 Indraccolo S, Stievano L, Minuzzo S, Tosello V, Esposito G, Piovan E, Zamarchi R, Chieco-Bianchi L, Amadori A: Interruption of tumor dormancy by a transient angiogenic burst within the tumor microenvironment. Proc Natl Acad Sci U S A 2006;103:4216-4221.

20 Folkins C, Shaked Y, Man S, Tang T, Lee CR, Zhu Z, Hoffman RM, Kerbel RS: Glioma tumor stem-like cells promote tumor angiogenesis and vasculogenesis via vascular endothelial growth factor and stromalderived factor 1. Cancer Res 2009;69:7243-7251.

21 Hillen F, Griffioen AW: Tumour vascularization: Sprouting angiogenesis and beyond. Cancer Metastasis Rev 2007;26:489-502.

22 Ferrer FA, Miller LJ, Andrawis RI, Kurtzman SH, Albertsen PC, Laudone VP, Kreutzer DL: Vascular endothelial growth factor (vegf) expression in human prostate cancer: In situ and in vitro expression of vegf by human prostate cancer cells. J Urol 1997;157:2329-2333.

23 Ferrer FA, Miller LJ, Andrawis RI, Kurtzman SH, Albertsen PC, Laudone VP, Kreutzer DL: Angiogenesis and prostate cancer: In vivo and in vitro expression of angiogenesis factors by prostate cancer cells. Urology 1998;51:161-167.

24 Ferrer FA, Miller LJ, Lindquist R, Kowalczyk P, Laudone VP, Albertsen PC, Kreutzer DL: Expression of vascular endothelial growth factor receptors in human prostate cancer. Urology 1999;54:567-572.

25 Weidner N, Carroll PR, Flax J, Blumenfeld W, Folkman J: Tumor angiogenesis correlates with metastasis in invasive prostate carcinoma. Am J Pathol 1993;143:401-409.

26 Li B, Sharpe EE, Maupin AB, Teleron AA, Pyle AL, Carmeliet P, Young PP: Vegf and plgf promote adult vasculogenesis by enhancing epc recruitment and vessel formation at the site of tumor neovascularization. FASEB J 2006;20:1495-1497.

27 Powell TM, Paul JD, Hill JM, Thompson M, Benjamin M, Rodrigo M, McCoy JP, Read EJ, Khuu HM, Leitman SF, Finkel T, Cannon RO, 3rd: Granulocyte colony-stimulating factor mobilizes functional endothelial progenitor cells in patients with coronary artery disease. Arterioscler Thromb Vasc Biol 2005;25:296-301.

28 Duda DG, Cohen KS, Kozin SV, Perentes JY, Fukumura D, Scadden DT, Jain RK: Evidence for incorporation of bone marrow-derived endothelial cells into perfused blood vessels in tumors. Blood 2006;107:2774-2776. 


\section{Cellular Physiology Cell Physiol Biochem 2015;37:253-268 \begin{tabular}{l|l|l}
\hline DOI: 10.1159/000430350 & C 2015 S. Karger AG, Basel
\end{tabular} \begin{tabular}{l|l} 
and Biochemistry Published online: August 20, 2015 & www.karger.com/cpb
\end{tabular}}

Huang/He/Peng/Li/Xu/Tang: Pristimerin Inhibits Bone Metastasis of PCa

29 Gao D, Nolan DJ, Mellick AS, Bambino K, McDonnell K, Mittal V: Endothelial progenitor cells control the angiogenic switch in mouse lung metastasis. Science 2008;319:195-198.

30 Gao D, Nolan D, McDonnell K, Vahdat L, Benezra R, Altorki N, Mittal V: Bone marrow-derived endothelial progenitor cells contribute to the angiogenic switch in tumor growth and metastatic progression. Biochim Biophys Acta 2009;1796:33-40.

31 Martin-Padura I, Gregato G, Marighetti P, Mancuso P, Calleri A, Corsini C, Pruneri G, Manzotti M, Lohsiriwat V, Rietjens M, Petit JY, Bertolini F: The white adipose tissue used in lipotransfer procedures is a rich reservoir of cd34+ progenitors able to promote cancer progression. Cancer Res 2012;72:325-334.

32 Buffa Filho W, Corsino J, Bolzani da SV, Furlan M, Pereira AM, Franca SC: Quantitative determination for cytotoxic friedo-nor-oleanane derivatives from five morphological types of maytenus ilicifolia (celastraceae) by reverse-phase high-performance liquid chromatography. Phytochem Anal 2002;13:7578.

33 Chang FR, Hayashi K, Chen IH, Liaw CC, Bastow KF, Nakanishi Y, Nozaki H, Cragg GM, Wu YC, Lee KH: Antitumor agents. 228. Five new agarofurans, reissantins a-e, and cytotoxic principles from reissantia buchananii. J Nat Prod 2003;66:1416-1420.

34 Niampoka C, Suttisri R, Bavovada R, Takayama H, Aimi N: Potentially cytotoxic triterpenoids from the root bark of siphonodon celastrineus griff. Arch Pharm Res 2005;28:546-549.

35 Tiedemann RE, Schmidt J, Keats JJ, Shi CX, Zhu YX, Palmer SE, Mao X, Schimmer AD, Stewart AK: Identification of a potent natural triterpenoid inhibitor of proteosome chymotrypsin-like activity and nfkappab with antimyeloma activity in vitro and in vivo. Blood 2009;113:4027-4037.

36 Wu CC, Chan ML, Chen WY, Tsai CY, Chang FR, Wu YC: Pristimerin induces caspase-dependent apoptosis in mda-mb-231 cells via direct effects on mitochondria. Mol Cancer Ther 2005;4:1277-1285.

37 Dirsch VM, Kiemer AK, Wagner H, Vollmar AM: The triterpenoid quinonemethide pristimerin inhibits induction of inducible nitric oxide synthase in murine macrophages. Eur J Pharmacol 1997;336:211-217.

38 Byun JY, Kim MJ, Eum DY, Yoon CH, Seo WD, Park KH, Hyun JW, Lee YS, Lee JS, Yoon MY, Lee SJ: Reactive oxygen species-dependent activation of bax and poly(adp-ribose) polymerase- 1 is required for mitochondrial cell death induced by triterpenoid pristimerin in human cervical cancer cells. Mol Pharmacol 2009;76:734-744.

39 Tang Y, Jacobi A, Vater C, Zou L, Zou X, Stiehler M: Icariin promotes angiogenic differentiation and prevents oxidative stress-induced autophagy in endothelial progenitor cells. Stem Cells 2015;33:1863-1877.

40 Peng X, Guo W, Liu T, Wang X, Tu X, Xiong D, Chen S, Lai Y, Du H, Chen G, Liu G, Tang Y, Huang S, Zou X: Identification of mirs-143 and -145 that is associated with bone metastasis of prostate cancer and involved in the regulation of emt. PloS one 2011;6:e20341.

41 Huang S, Guo W, Tang Y, Ren D, Zou X, Peng X: Mir-143 and mir-145 inhibit stem cell characteristics of pc-3 prostate cancer cells. Oncol Rep 2012;28:1831-1837.

42 Tang Y, Vater C, Jacobi A, Liebers C, Zou X, Stiehler M: Salidroside exerts angiogenic and cytoprotective effects on human bone marrow-derived endothelial progenitor cells via akt/mtor/p70s6k and mapk signalling pathways. Br J Pharmacol 2014;171:2440-2456.

43 Huang S, Tang Y, Cai X, Peng X, Liu X, Zhang L, Xiang Y, Wang D, Wang X, Pan T: Celastrol inhibits vasculogenesis by suppressing the vegf-induced functional activity of bone marrow-derived endothelial progenitor cells. Biochem Biophys Res Commun 2012;423:467-472.

44 Bisson I, Prowse DM: Wnt signaling regulates self-renewal and differentiation of prostate cancer cells with stem cell characteristics. Cell Res 2009;19:683-697.

45 Miki J, Furusato B, Li H, Gu Y, Takahashi H, Egawa S, Sesterhenn IA, McLeod DG, Srivastava S, Rhim JS: Identification of putative stem cell markers, cd133 and cxcr4, in htert-immortalized primary nonmalignant and malignant tumor-derived human prostate epithelial cell lines and in prostate cancer specimens. Cancer Res 2007;67:3153-3161.

46 Dubrovska A, Kim S, Salamone RJ, Walker JR, Maira SM, Garcia-Echeverria C, Schultz PG, Reddy VA: The role of pten/akt/pi3k signaling in the maintenance and viability of prostate cancer stem-like cell populations. Proc Natl Acad Sci U S A 2009;106:268-273.

47 Pfeiffer MJ, Schalken JA: Stem cell characteristics in prostate cancer cell lines. Eur Urol 2010;57:246-254.

48 Zoller M: Cd44: Can a cancer-initiating cell profit from an abundantly expressed molecule? Nat Rev Cancer 2011;11:254-267. 


\section{Cellular Physiology Cell Physiol Biochem 2015;37:253-268 \begin{tabular}{c|c}
\hline DOI: 10.1159/000430350 & (C) 2015 S. Karger AG, Basel
\end{tabular} \begin{tabular}{l|l} 
and Biochemistry Published online: August 20, 2015 & www.karger.com/cpb
\end{tabular}}

Huang/He/Peng/Li/Xu/Tang: Pristimerin Inhibits Bone Metastasis of PCa

49 Su YJ, Lai HM, Chang YW, Chen GY, Lee JL: Direct reprogramming of stem cell properties in colon cancer cells by cd44. ЕMBO J 2011;30:3186-3199.

50 Lazar-Molnar E, Hegyesi H, Toth S, Falus A: Autocrine and paracrine regulation by cytokines and growth factors in melanoma. Cytokine 2000;12:547-554.

51 Anderson GM, Nakada MT, DeWitte M: Tumor necrosis factor-alpha in the pathogenesis and treatment of cancer. Curr Opin Pharmacol 2004;4:314-320.

52 Sheen-Chen SM, Chen WJ, Eng HL, Chou FF: Serum concentration of tumor necrosis factor in patients with breast cancer. Breast Cancer Res Treat 1997;43:211-215.

53 Aggarwal BB, Shishodia S, Sandur SK, Pandey MK, Sethi G: Inflammation and cancer: How hot is the link? Biochem Pharmacol 2006;72:1605-1621.

54 Saijo Y, Tanaka M, Miki M, Usui K, Suzuki T, Maemondo M, Hong X, Tazawa R, Kikuchi T, Matsushima K, Nukiwa T: Proinflammatory cytokine il-1 beta promotes tumor growth of lewis lung carcinoma by induction of angiogenic factors: In vivo analysis of tumor-stromal interaction. J Immunol 2002;169:469475.

55 Weinreich DM, Elaraj DM, Puhlmann M, Hewitt SM, Carroll NM, Feldman ED, Turner EM, Spiess PJ, Alexander HR: Effect of interleukin 1 receptor antagonist gene transduction on human melanoma xenografts in nude mice. Cancer Res 2003;63:5957-5961.

56 Wedge SR, Ogilvie DJ, Dukes M, Kendrew J, Chester R, Jackson JA, Boffey SJ, Valentine PJ, Curwen JO, Musgrove HL, Graham GA, Hughes GD, Thomas AP, Stokes ES, Curry B, Richmond GH, Wadsworth PF, Bigley AL, Hennequin LF: Zd6474 inhibits vascular endothelial growth factor signaling, angiogenesis, and tumor growth following oral administration. Cancer Res 2002;62:4645-4655.

57 Dimmeler S, Fleming I, Fisslthaler B, Hermann C, Busse R, Zeiher AM: Activation of nitric oxide synthase in endothelial cells by akt-dependent phosphorylation. Nature 1999;399:601-605.

58 Zachary I, Gliki G: Signaling transduction mechanisms mediating biological actions of the vascular endothelial growth factor family. Cardiovasc Res 2001;49:568-581.

59 Deeb D, Gao X, Liu YB, Pindolia K, Gautam SC: Pristimerin, a quinonemethide triterpenoid, induces apoptosis in pancreatic cancer cells through the inhibition of pro-survival akt/nf-kappab/mtor signaling proteins and anti-apoptotic bcl-2. Int J Oncol 2014;44:1707-1715.

60 Gao X, Liu Y, Deeb D, Arbab AS, Gautam SC: Anticancer activity of pristimerin in ovarian carcinoma cells is mediated through the inhibition of prosurvival akt/nf-kappab/mtor signaling. J Exp Ther Oncol 2014;10:275-283.

61 Liu YB, Gao X, Deeb D, Arbab AS, Gautam SC: Pristimerin induces apoptosis in prostate cancer cells by down-regulating bcl-2 through ros-dependent ubiquitin-proteasomal degradation pathway. J Carcinog Mutagen 2013;6:005.

62 Wei W, Wu S, Wang X, Sun CK, Yang X, Yan X, Chua MS, So S: Novel celastrol derivatives inhibit the growth of hepatocellular carcinoma patient-derived xenografts. Oncotarget 2014;5:5819-5831. 